\title{
CONGESTION IN POPULAR TOURIST AREAS: A MULTI-ATTRIBUTE EXPERIMENTAL CHOICE ANALYSIS OF WILLINGNESS-TO-WAIT IN AMSTERDAM
}

Patrizia Riganti

School of the Built Environment University of Nottingham

UK
Peter Nijkamp

Department of Spatial Economics

Free University, Amsterdam

The Netherlands

\begin{abstract}
Many mature and popular tourist destinations are attracting large volumes of tourist flows. Especially during peak periods this may lead to congestion phenomena in different areas of tourist cities. This paper presents the results of a tourist survey carried out in the city centre of Amsterdam, during the high tourist season (2006), when congestion phenomena are clearly present. In addition to a descriptive and exploratory statistical analysis based on multi-attribute choice analysis, the paper also presents the findings from a statistical choice experiment based on the concept of willingness-to-accept tourism congestion. Various interesting results are discussed, with a specific focus on the question how these results can feed into the policy debate to manage congestion in mature cultural destinations.
\end{abstract}




\section{The Scope of Modern Tourism}

Tourism has over the years grown into an economic sector of major significance. At an average global level, tourism is - directly and indirectly - responsible for some 12 percent of GNP over all countries, as well as for about 200 million jobs. It is also responsible for a large portion of modern international passenger transport (see Theobald 2005). Tourism comprises a wide array of economic activities and may be conceived as “...the temporary movement of people to destinations outside their normal place of work or residence, the activities undertaken during their stay in those destinations, and the facilities created and services provided to cater to their needs" (see Wall and Mathieson 2006, p. 1). Normally, tourism is a luxury and voluntary activity, not only in Europe ('Leisuropia'), but also elsewhere.

The rise of the tourist industry has to be seen against the background of farreaching changes in our industrial society. In particular, the development of the leisure society has created the conditions for the modern creative industry in which arts, media, entertainment, culture, communications and knowledge-driven activities play an important role. Many cities regard the creative industry as a corner stone for innovative development and urban gentrification (see Florida 1995). Creative economic clusters are increasingly coming to the fore in cultural quarters of cities, which show a surprising parallel to industrial districts addressed more than a century ago by the great economist Alfred Marshall (see also Mommaas 2004, Montgomery 2003, or Tallon et al. 2006). The leisure and culture basis of many modern cities is strongly supported by tourism.

Environmental awareness and cultural emancipation have - paradoxically - been important stimuli for the age of mass tourism in which rising tourist flows to places of environmental and cultural interest (often referred to as ecotourism) can be observed, even though the related spatial mobility and tourist pressure have caused significant global and local externalities (see also Honey 1999 and Buckley 2004).

In the past decades, tourism has clearly turned into a creative economic sector driven by consumer motivations in which the idea to get exposed to something new or original in a relaxed way is prominently present (see McCabe 2000). It may adopt different forms, e.g. cultural heritage tourism, performing arts tourism, sports tourism, beach tourism, nature tourism and so forth. The nexus of increasing leisure time, low cost transport modes and increasing mobility has prompted a global development towards creative tourism industries. And many cities have designed policies to attract a substantial share of global tourist flows for their own benefit (e.g. Berlin, Venice, Cape Town, San 
Francisco or Amsterdam). Consequently, tourist policy is driven by strong competitive forces (see e.g., Crouch and Ritchie 1999, and Giaoutzi and Nijkamp 2006).

As a result of the above factors, tourism has developed into an important driving force for cities' economic growth, and consequently, its impacts - both economic and environmental ones - need to be assessed within a broader sustainability framework. Tourism accounts for $5 \%$ of all jobs and 5\% of all consumer expenditure within the European Union, is one of Europe's largest economic sectors and features among the largest key industries of the 21st century. The World Tourism Organization estimates that the number of arrivals in Europe will double to 720 million tourists per year by the year 2020. Cultural and ecological tourism is an important form of tourism that is expected to witness the highest growth in the future. This is being fuelled by changing patterns of tourism (more vacations, shorter stays), the availability of cheap airfares, and the popularity of and access to ICT-based tourist services.

Since the early 1990s, European towns and cities have shown an increased interest in developing cultural tourism strategies as a wheel for urban economic growth. These policies have often helped revive waning urban centers and bringing life to declining local communities and economies. Decentralisation has significantly favoured this process by allowing urban governments to promote local tourism. Local cultural heritage is seen as a capital, a resource to manage. However, in order to manage this capital in a sustainable manner, it is necessary to account for the needs of tourists and residents alike. These needs are often conflicting, and overcoming them poses a major challenge to urban managers and decision-makers. Non-market economic valuation can help understand the relevance and the potential economic impacts brought by the nature of this conflict (see also Alberini et al. 2003, Carruthers and Mundy 2006, and Noonan 2003). Experimental choice analysis can help to assess the marginal utility associated with the multiplicity of attributes expressing the tourists' experience and satisfaction as well as the quality of life of the residents faced with the tourists' presence, especially in a mature tourist destination characterized by tourist congestion.

Many small- and medium-sized cities have appeared on the tourism map only in recent years, while other cultural sites have attracted tourists for centuries. Therefore, it is possible to distinguish between more traditional, 'mature', and 'non-mature' tourism destinations. Cities like Venice, Rome, Paris and Amsterdam fall in the first category. Though some of the impacts that the two categories face are similar, mature tourist destinations witness more frequently the negative environmental externalities associated with issues of overcrowding or congestion. These diseconomies of density are increasingly becoming a source of concern for the tourism sector. 
It becomes important to discern which are the attraction and repulsion factors of modern tourism in mature tourist destinations. Which features make a city a popular tourist resort? Therefore, there is a need to study in more detail the motives of visitors to a given city in order to extract from micro research their behavioral choices. Since tourist cities are involved in a fierce global competition for the favour of tourists/visitors, for marketing purposes it is essential to identify the critical key factors of tourist attractiveness (both positive and negative). This may relate to the true objective characteristics of the site, but also to the service quality offered or perceived, or to externalities (e.g., tourism congestion) caused by fellow tourists. From this perspective, stated preferences economic valuation techniques can help ascertain both the negative and positive factors that might impair or enhance tourist experience. Applications are quite limited, hence there is the need to develop statistical data bases that would allow for applied micro-based choice modeling experiments usually analyzed by means of logit or probit models.

\section{Cultural Tourism and Mature Destinations}

Tourism is thus a center piece of a globalizing economy: it is not only the outgrowth of a wealthy leisure society, it is also directly associated with the rise in mobility in modern welfare society. The assessment of the economic value of tourism is therefore essentially based on spatial interaction analysis, in which the site-specific economic benefits are to be evaluated through proper monetary-economic or complementary socio-economic indicators (cf. Hanley et al. 1998). One popular approach, with a long standing tradition and frequently deployed in empirical research, is the so-called travel cost method. Other - sometimes complementary - approaches are hedonic prices and social cost-benefit analysis, while in the past decades we have witnessed an increasing popularity of contingent valuation methods based on experimental design and survey questionnaires. The spatial component in the latter class of methods is not always strongly developed and calls for adjusted estimation techniques (e.g., spatial autocorrelation analysis). Another popular class of current assessment methods is conjoint analysis which has prompted much interest in micro-economic research and choice theory. This method has potentially a great relevance in tourism research, as it may be instrumental in identifying the key factors for a choice of tourist destination as well as the driving forces of tourist behavior (e.g., the choice of tourist facilities in a given tourist place). 
As indicated above, tourism manifests itself in different modalities (e.g., nature tourism, urban tourism, beach tourism, health tourism, cultural heritage tourism etc.). Cultural heritage assets act as attractor of tourists' flows, thus representing a local capital which has the capacity to act as a catalyst for local economies. Cultural tourism may have a multiplier effect on the local economy, and when appropriately managed it can promote the economic growth of other related sectors, such as hotels, restaurants, transportation, arts, exhibitions, environment etc., although this has not always been the case for many European destinations, in particular for those which have attracted substantial numbers of tourists, usually defined as mature mass-tourism destinations. Many of these "traditional" tourist destinations have witnessed unsustainable growth of tourists' flows and this may have severe impacts on the quality of life of urban residents. Some cities like Venice, Paris and Amsterdam, to mention a few, enjoy massive volumes of tourists and are in need to manage differently their tourist flows. Being highly in demand, they may need to modify the tourist offer, e.g., by creating alternative tourist routes or new attractive facilities.

Modern tourism may thus have a big impact on urban communities. Some heritage sites can be overwhelmed by the tourists' presence, especially day trippers who visit the site without contributing substantially to the local economy, whilst some others have the potential of creating an attractive offer that has as yet not been developed. From an economic point of view, one has to find a balance between the demand and supply side of the tourism market in these regions. Urban and regional strategies may have to be developed aiming to create a balance at the supply side, in order to minimize the negative externalities brought by excessive numbers of tourists and to spread more evenly the tourists' flows with their benefits. A first step needs to be the study of the economic impacts of the tourists' presence, understanding also the environmental and social impacts brought by severe situations of tourist congestion, and using sites' carrying capacity as a possible management tool. In other words, one needs to devise tourism strategies that are sustainable from a social and economic point of view. This calls for proper insight into tourism motives including situations of externalities (such as congestion).

\section{Congestion in Cultural Destinations}

Mass tourism may lead to excessive spatial concentration of tourists in popular resorts or sites. Tourism congestion at destinations - and particularly at natural and cultural sites - can cause an accumulation of negative impacts, resulting, for instance, in a major reduction in the visitors' enjoyment and appreciation of the site. The presence of 
congestion may bring about adverse impacts on conservation programmes for a historical site, may cause damage to flora, fauna, scenic views, the physical fabric or special values of the site, increase litter and pollution, strain the capacity of local infrastructure, and diminish the efficiency of tourism services. All these effects can reduce the opportunities for visitors to spend money locally and can generate considerable stress on the local community through competition for local services. Clearly, modern tourism is in the centre of sustainability issues.

Any analysis of sustainable development in an urban context calls for an operational welfare-analytic perspective. In order to assess the extent to which a site suffers from congestion, recent studies (see e.g., WTO 2004) have developed a number of indicators of congestion at cultural sites. Indicators like the ratio of local population to tourists during peak and off-peak seasons, the number of tourists per square meter of the site, or the percentage of tourists who believe that the destination is too crowded when questioned using an exit questionnaire, are among the most commonly used. There is a clear need for a proper conceptual demarcation of indicators used.

From an economic point of view, congestion occurs when either the utility of one person or actor diminishes due to the presence or the behaviour of other persons, or when the costs of undertaking an activity rise due to the presence of other persons. Congestion thus incorporates time waited in line or in traffic to access the site, the number of people per unit of space, the excess of waste in densely populated areas, to mention only a few.

Congestion may formally be represented as follows (Jakus and Shaw 1997):

$$
U_{i}=f_{i}\left(\underline{a}_{i}, \underline{a}_{j}\right), \quad j=1, \ldots, J ; j \neq i
$$

where $\underline{a}_{i}$ represents a set of variables denoting actions (behavioural decisions, e.g.) of actor $i$ and where $U_{i}$ represents the corresponding utility level of the same actor. Equation (1) indicates that - beyond a certain critical threshold level caused by capacity limits on the supply side - inter-actor externalities may emerge.

Congestion is thus one of the obvious examples of economic externalities and has been studied extensively in transportation economics. The following quotation may be helpful: "Congestion in transportation is, of course, not limited to roads: it is also a problem at airports and in the airways, at harbours, on inland waterways, on railways, and for travelers on buses and subway networks. For modelling purposes useful parallels can often be drawn between traffic congestion and congestion at other facilities. Broadly speaking, traffic congestion occurs when the cost of travel is increased by the presence of 
other vehicles, either because speeds fall or because greater attention is required to drive safely" (Lindsey and Verhoef 2000, p. 354).

In general, any situation where there is a lack of capacity in case of multiple users may imply a case of congestion. And popular tourist sites are a clear example of this interactive behaviour in which both market and non-market impacts may prevail (see e.g., Coccossis and Mexa 2004, McConnell 1988, O’Reilly 1986, and Saveriades 2000). Is it possible to identify tourism congestion indicators, (e.g., waiting time to enter attractions, willingness-to-pay to avoid congestion externalities, or willingness-to-accept them) and to trace their impact on tourist experience, satisfaction or behaviour (including economic effects)? This will be the main research question in the present paper in which tourism congestion in the high season in Amsterdam is taken as an application field.

\section{Tourism in Amsterdam: A General Sketch}

Amsterdam has become one of the popular global tourist destinations with more than 7 million overnight stays annually, but also as a place where congestion phenomena in the high tourist season abound. The cross-streets lined with shops, café's, creative businesses and cultural venues exhibit a lively but also overcrowded picture. The city houses a wealth of varied cultural heritage (historical architecture, museum, arts exhibitions etc.). Various cultural facilities (such as the Van Gogh Museum, the Rijksmuseum or the Anne Frank House) are attracting so many visitors that - sometimes long - waiting times cannot be avoided. The same holds for the hospitality sector in the summer time.

The Amsterdam tourist market has a strong foreign component, with $89 \%$ of all overnight stays by visitors from abroad, with the following subdivision: Great Britain (25\%), Germany (7\%), France (4\%), Spain (6\%), Italy (5\%), United States (13\%), and the rest of the world (29\%). The domestic market has clearly a strong business nature, given the strong commercial sector of Amsterdam.

Tourism is a major source of income for the city of Amsterdam and supports the concept of Amsterdam as 'the creative city'. But negative externalities in the form of tourism congestion may do harm to the image, the performance and the future position of Amsterdam as an attractive city for many visitors from all over the world. In recent years - after September 2001 - Amsterdam has witnessed a slight decline in the volume of tourists (1\% to 5\%), although tourist expenditures showed a rise from 3.1 billion euro's in 2000 to 4.1 billion euro's in 2003. In general, tourists tend to stay for shorter periods, but to spend more. Nevertheless, Amsterdam has also seen a decline of its position on the 
ranking list of European cities; it ranks now after London, Paris, Rome, Dublin, Prague and Barcelona. Give the important socio-economic benefits of tourism - with approximately 38.000 jobs in this sector - it is conceivable that city authorities do their utmost to enhance the significance of tourism for the urban economy. As mentioned in the introductory section, tourism is an internationally competitive economic sector and hence, the city has recently launched AMSTERDAM TOP!, a plan for intensified tourism marketing for the period 2005-2008, with the following goals:

- $\quad$ an increase in the number of overnight stays of $8 \%$ in this period (i.e., about $2 \%$ a year);

- $\quad$ a rise in total tourism and business expenditures of the same order of magnitude, which would mean a total expenditure by visitors to the city of approximately 4.3 billion euro in the year 2008;

- $\quad$ a stationary number of daily visitors to the city, viz. 12 million visitors every year.

To achieve these goals, the tourist marketing efforts for the city are annually centered on major themes, such as 'Amsterdam and water' (2005) or 'the Rembrandt year' (2006). This seems to be a proper approach to attract old and new visitors to the city. In combination with further product diversification, a rising number of tourists and visitors may be expected, but at the time this may aggravate the tourism congestion in the city.

\section{Methodology and Data Base}

Any marketing strategy for Amsterdam has to take into consideration the peculiarities of the city of Amsterdam, with a strong and internationally recognized image as a city of culture and creativity (museums, performing arts, architecture), a city of 'blue architecture' (canals and water), a city with historical buildings and monuments, and a city of social contact (a liveable place, a meeting point for friends, a pleasant and liberal atmosphere etc.). But how do tourists evaluate the attractiveness of the city against the background of congestion externalities?

Clearly, tourism has a wide variety of both market and non-market impacts. In the methodology of tourism economic research various assessment approaches and methods are distinguished and deployed, with a major distinction between revealed and stated preference methods, and specific evaluation techniques such as the travel cost method, the hedonic pricing method, contingent valuation methods (based on either willingness-to pay or willingness-to-receive format, and encompassing other multiattribute choice 
methods such as conjoint analysis) and multicriteria methods (see e.g., Towse an Khakee 1991, Epstein 2003, Navrud and Ready 2002, or Throsby 2003). In the present paper we will adopt a rather novel approach, based on the willingness-to-wait (WTW) in congested tourist places/sites/facilities. Tourism congestion means loss of time and may assume different forms (e.g., waiting in a line to enter, long waiting time to be served, high density of tourists leading e.g. to decline in privacy), different types (e.g., permanent congestion, fluctuating congestion) and different effects (e.g., disturbance to local residents, rise in pollution or noise). Even though the perceived benefits of a tourist visit to a given place may be higher than the foreseen or actual costs (including congestion externalities), loss of time may cause considerable (monetary or psychological) costs to visitors (see O’Reilly 1986, Saveriades 2000). The WTW concept takes for granted the prevalence of the demand side of the tourist market and aims to assess the willingness of tourists to wait before a certain tourist service (e.g., a museum visit, a guided walking tour, a visit to a restaurant or pub) can be enjoyed. The idea is to use stated preference methods to elicit attitudes/preference/perceptions of tourists in a popular and congested tourist destination in order to shed light on the visitor's satisfaction.

Our case study for the city of Amsterdam is based on data collected during the congested tourist season in early summer 2006. The data stem from a set of structured interviews held among visitors to this tourist place. The aim was to collect information on attitudes and behaviour of cultural tourists, as well as on impacts and management issues related to visits to popular, but congested tourist sites in the city.

In addition to a variety of individual background data on characteristics of tourists, their preferences, activity patterns and expenditure categories, an experimental choice analysis was performed - based on hypothetical stated preference questions regarding alternative choice scenarios in case of tourism congestion - in order to assess their WTW.

The following data categories were amongst others distinguished:

- $\quad$ resident or visitor;

- $\quad$ involvement in local cultural heritage or environmental protection in home town;

- $\quad$ motives for choice of tourist destination;

- $\quad$ perceived effects of tourism;

- $\quad$ attributes of congestion for residents (including suggested remedial actions and advantages);

- $\quad$ attributes of congestion for visitors (including suggested remedial actions and advantages); 
- $\quad$ pairwise choice from experimental scenarios on tourism management (for both residents and tourists);

- $\quad$ priority ranking of attributes of tourism congestion;

- $\quad$ maximum acceptable waiting time for items of tourist choice;

- $\quad$ use of travel modes to go to Amsterdam;

- $\quad$ use of travel modes to get around in Amsterdam;

- $\quad$ reasons for visiting Amsterdam;

- $\quad$ organization of holiday trip (package, semi-package, self-organized);

- $\quad$ costs of holiday package and items included;

- $\quad$ other tourist visits outside Amsterdam;

- $\quad$ length of stay in the city;

- $\quad$ type of accommodation;

- $\quad$ meal habits and use;

- $\quad$ expenditure on tourist items;

- $\quad$ judgment of the quality of various tourist services;

- $\quad$ personal information on the visitor (e.g., country of origin, age, income, education etc.).

The actual number of statistically useful interviews in our Amsterdam study is 156, so that a proper statistical analysis can be conducted. The results of this field investigation are presented in the next section.

\section{Results of WTW Analysis}

In this section we will present and interpret the main statistical results from our survey questionnaire. We will first offer some descriptive findings from the data set on the interviewees (see Tables 1 and 2). Table 1 reveals some interesting features of our sample. There is a slight male dominance among the visitors of Amsterdam. Next, there is quite some interest of these visitors in cultural and environmental activities (initiatives in their home country or home town). This profile is supported by the relatively high educational level of these visitors; more than 50 percent has a university degree. The share of students and tourists having a job is also rather high (about 80\%). Table 2 also reveals interesting elements: the age profile is rather young, while the average income of the Amsterdam tourists is rather high. Such information is of course of key importance for marketing efforts. 
Table 1. Characteristics of interviewees in the sample

\begin{tabular}{|l|l|}
\hline Variable & Percentage \\
\hline Gender & \\
- Male & 57.1 \\
- Female & 42.9 \\
\hline Involvement in local cultural initiatives & \\
- Yes & 28.2 \\
- No & 71.8 \\
\hline Member of environmental conservation organization & \\
- Yes & 37.8 \\
- No & 62.2 \\
\hline Education & \\
- Grammar school & 2.6 \\
- High school & 16.0 \\
- College & 28.2 \\
- College graduate & 25.6 \\
- Postgraduate & 27.6 \\
\hline Job/economic status & \\
- Student & 22.4 \\
- Employed & 58.3 \\
- Retired & 10.3 \\
- Unemployed & 6.4 \\
- Other & 2.6 \\
\hline
\end{tabular}

Table 2. Age and income data of interviewees in the sample

\begin{tabular}{|l|c|c|c|}
\hline Socio-economic indicator & Mean Value & Minimum & Maximum \\
\hline Age & 38 & 18 & 83 \\
Income (in euros) & 31,474 & 10,000 & 60,000 \\
\hline
\end{tabular}

The previous findings prompt of course a question on the general motivation to travel by the relevant group of visitors. This information is offered in Figure 1, which gives a frequency distribution - by gender - of 5 major motives to travel in general.

Although there are some differences between male and female visitors to Amsterdam, the overall pattern is rather uniform: there is a clear preference for cultural heritage (which is supported by the findings from Tables 1 and 2), followed by relaxed nature tourism (sun and sea). Gastronomy appears to score very low.

The previous information on general motives of tourists to travel was next more focussed by asking why these visitors have chosen explicitly Amsterdam as their tourist destination. These results are included in Figure 2. It appears that holiday trips are the most important motive for visiting Amsterdam (which is in agreement with the general attractiveness profile of the city), while also visiting friends and relatives (so-called VFR- 


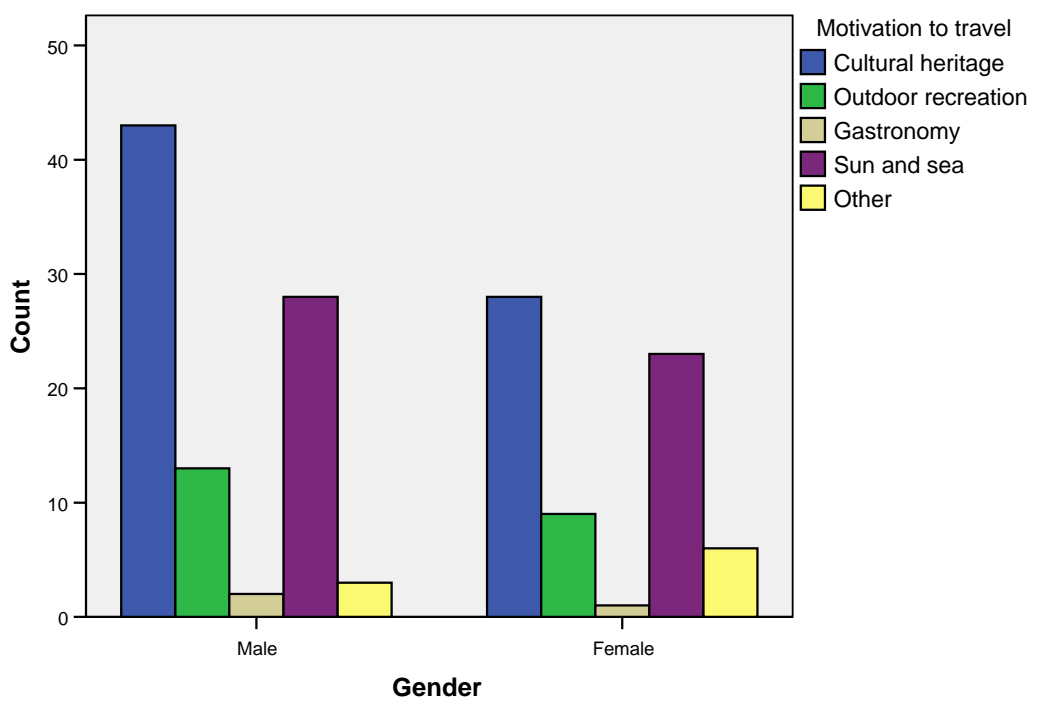

Figure 1. Motivation to travel by gender

tourism; see Poel et al. 2006) scores relatively high. There is a rather high proportion of remaining motives that cannot be clearly identified in one cluster. Business trips appear to score rather low as a motive to visit Amsterdam. In a complementary question, the visitors were asked whether Amsterdam was the exclusive destination of their travel; it appeared that multi-city trips were rather rare (approximately 95\% of the visitors had Amsterdam as their sole destination).

It is also interesting to find out whether the type of transport mode used is exhibiting a special profile for the visitors of Amsterdam. This information is contained in Figure 3. It is surprising that the largest share of tourists (almost 50 percent) is arriving by train in Amsterdam, in contrast to the general perception that most tourists would arrive by plane. Also visitors using a car (rented or owned) are clearly a minority.

Next, we present statistical data on the trip organization of tourists in Amsterdam (see Tables 3-5). Table 3 shows that the majority of tourists enjoy their lunch and dinner in a restaurant, so that during the tourist peak season congestion in restaurants may take place. 


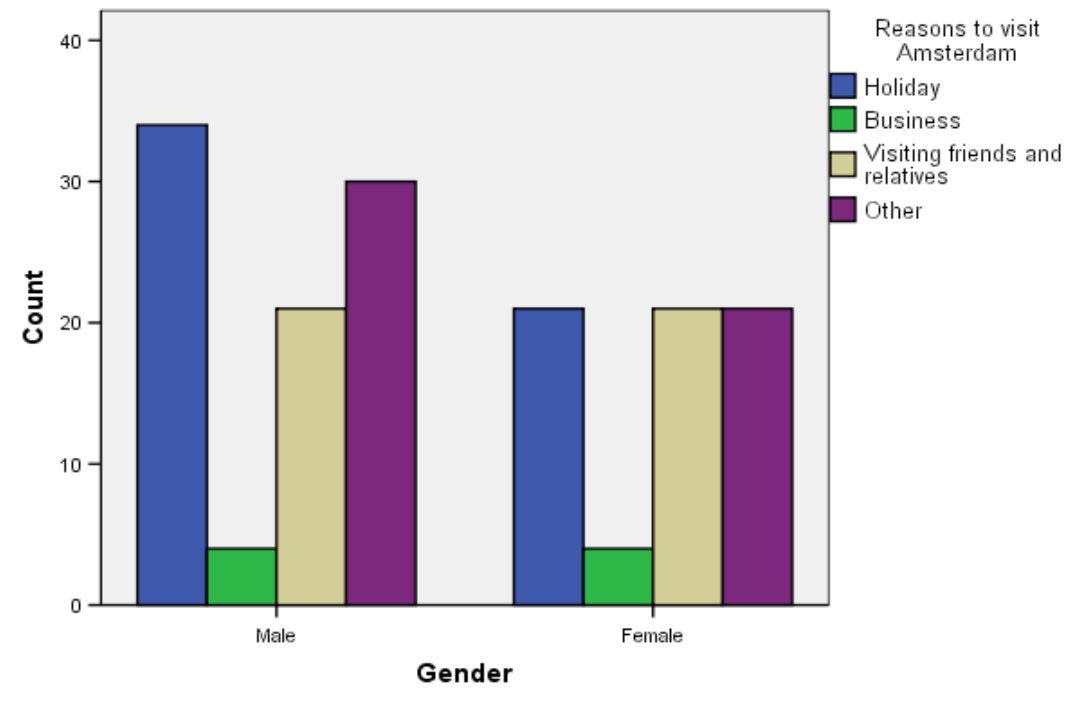

Figure 2. Motivation to visit Amsterdam by gender

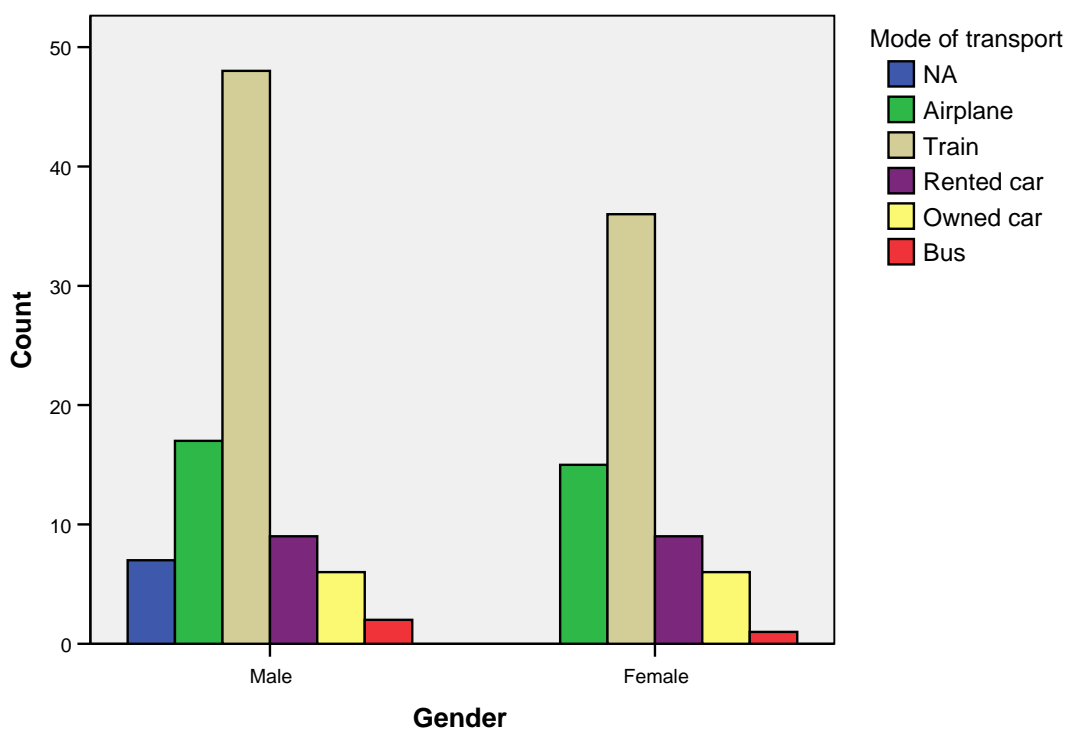

Figure 3. Mode of transport to Amsterdam by gender 
Table 3. Organization of meals by visitors

\begin{tabular}{|ll|c|}
\hline Meal categories & Percentage \\
\hline Breakfast at: & Hotel & 26.3 \\
& Restaurant & 10.9 \\
& Self & 62.8 \\
\hline Lunch at: & Hotel & 1.9 \\
& Restaurant & 56.4 \\
& Self & 41.7 \\
\hline Dinner at: & Hotel & .6 \\
& Restaurant & 60.9 \\
& Self & 38.5 \\
\hline
\end{tabular}

Table 4. Duration of stay in various accommodation categories

\begin{tabular}{|l|l|}
\hline Accommodation & Mean \\
\hline Days in Amsterdam & 3 \\
Nights in Amsterdam & 2 \\
Hotel & 5 \\
Bed and Breakfast & 0 \\
Hostel & 1 \\
Campingsite & 0 \\
Rented flat & 1 \\
Owned flat & 0 \\
Friends & 2 \\
\hline
\end{tabular}

Table 5. Action radius of tourists

\begin{tabular}{|ll|c|}
\hline Spatial orientation & Percentage \\
\hline Visiting Amsterdam region: & No & 87.2 \\
& Yes & 12.8 \\
\hline Visiting province: & No & 85.9 \\
& Yes & 14.1 \\
\hline Visiting other regions: & No & 84.0 \\
& Yes & 16.0 \\
\hline
\end{tabular}

Next, Table 4 demonstrates that the average duration of stay of visitors to Amsterdam is rather short, showing that our sample is in tune with the general statistics. Apparently the small geographical scale of the historical part of the city allows them to visit many sites in a limited number of days, provided there is no overconcentration of visitors.

Then, from Table 5 we can derive that most tourists choose Amsterdam as their exclusive destination, so that almost all facilities are to be enjoyed in the city itself. This fact indicates once more that tourist congestion may be a source of concern for the city. 
The issue of congestion and the willingness to wait by visitors will be investigated later on in Section 7.

Finally, Table 6 contains cost expenditure data for the visitors to Amsterdam. There appears to be quite some variation among tourists for the various expenditure categories. The most important components - apart from travel - are accommodation, meals, transportation, shopping and entertainment. These are also the categories where congestion phenomena are most likely to occur. Consequently, a further analysis of tourist congestion in Amsterdam is certainly relevant.

Table 6. Composition of trip costs/expenditures of visitors

\begin{tabular}{|l|r|l|l|}
\hline & Mean & Minimum & Maximum \\
\hline Estimated trip cost & 705 & 0 & 1500 \\
Cost accommodation per day & 38 & 0 & 700 \\
Cost accommodation per trip & 151 & 0 & 1860 \\
Cost meals per day & 33 & 0 & 250 \\
Cost meals per trip & 102 & 0 & 1500 \\
Cost transportation per day & 69 & 0 & 1250 \\
Cost transportation per trip & 85 & 0 & 1250 \\
Cost entertainment per day & 14 & 0 & 100 \\
Cost entertainment per trip & 42 & 0 & 600 \\
Cost tours per day & 7 & 0 & 100 \\
Cost tours per trip & 20 & 0 & 200 \\
Local crafts per day & 5 & 0 & 100 \\
Local crafts per trip & 8 & 0 & 150 \\
Cost shopping per day & 67 & 0 & 1000 \\
Cost shopping per trip & 92 & 0 & 1000 \\
Cost other items per day & 4 & 0 & 450 \\
Cost other items per trip & 14 & 0 & 1500 \\
\hline
\end{tabular}

\section{Analysis of Tourist Congestion and Willingness to Wait}

The presence of large numbers of tourists in Amsterdam may negatively affect the quality of the tourist experience in the city. In particular, two types of negative externalities may occur, viz. long queues at entrances of tourist attractions, and long waiting times in cafés, bars and restaurants (or even shops). In the light of the abovementioned specific profile of tourist visitors in Amsterdam it is, therefore, 


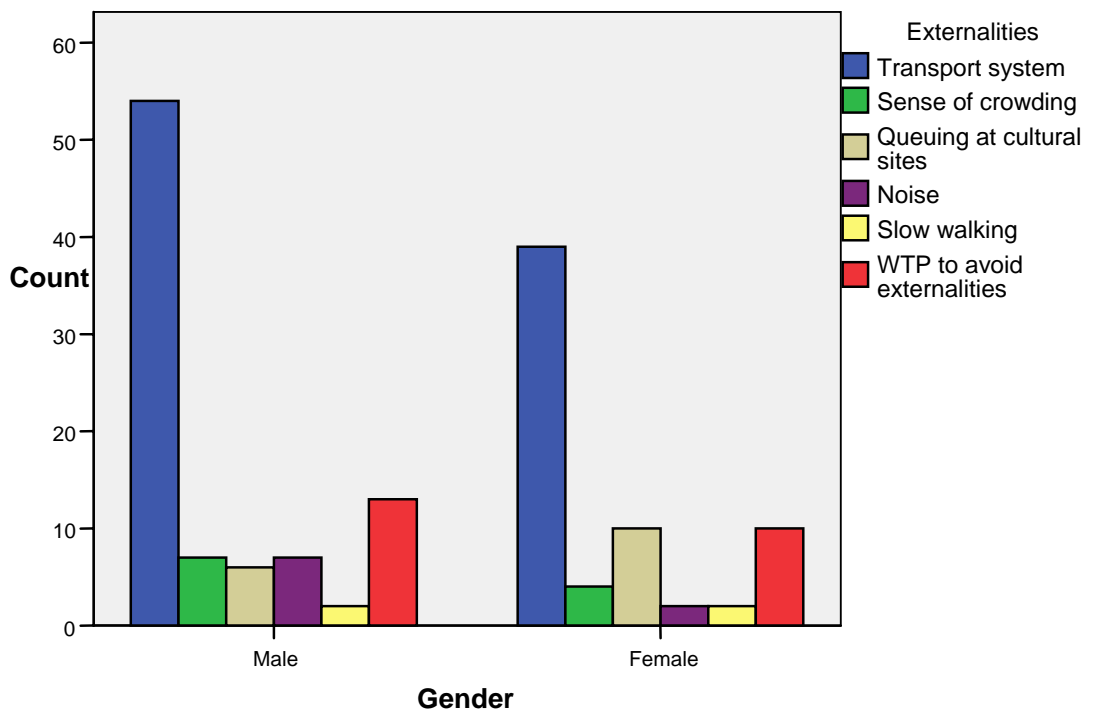

Figure 4. Frequency distribution of tourist externalities by gender

interesting to analyze the perceptions of tourists regarding these two types of spatial externalities. The method deployed in our empirical study is based on a stated preference questionnaire, in which tourists are shown various scenarios illustrating possible crowding externalities brought by situations of congestion in the city of Amsterdam. The attributes expressing congestion in the city were identified during the implementation of a pretest questionnaire where tourists were asked directly to mention the aspects of congestion that they regarded more evident in Amsterdam (tourists were interviewed in the vicinity of congested sites). In the final questionnaire we presented respondents different scenarios expressing congestion externalities and ways to avoid or solve them. The final survey was administrated in person on a computer, by one interviewer who gathered a total of 156 interviews. A computer interface was developed to make the presentation and sequence of the questions easier. The questionnaire was quite complex and aimed to gather a wealth of information, and therefore the interface made possible to do so in a shorter time compared to a traditional paper questionnaire.

The scenarios were illustrated by pictures. In total, five images were shown on: queuing at cultural site entrances, sense of crowding in narrow streets, slow walking in congested areas, noise in overcrowded places, and congestion in public transport. For these five tourist congestion issues two different possible tourism management policy packages were designed to minimize the negative impacts of large numbers of tourists 
and to improve the overall tourist experience in Amsterdam. Various actions to cope with these externalities include inter alia: increase the capacity of public transport, mark alternative routes for tourists in congested areas, improve ticket services at cultural sites etc. Figure 4 maps out the frequency distribution (in absolute numbers) of the virtual perception of various negative tourist externalities by gender based on the above described experimental scenario analysis. Public transport - used by almost all visitors appears to be a severe source of disturbance, for both men and women, so that capacity improvement seems to be a logical policy response.

As mentioned above, we will now present the results from our WTW analysis, where the question was asked how many minutes waiting time would acceptable at two types of tourist facilities, viz. (entrance to) tourist sites (museums etc.) and queuing at café's, bars and restaurants. The frequency distributions of these statistical findings are shown in Figures 5 and 6. The results show that the acceptable waiting time at café's, bars and restaurants is significantly lower than at the entrance of tourist cultural facilities, a finding that is consistent with the cultural image of Amsterdam.

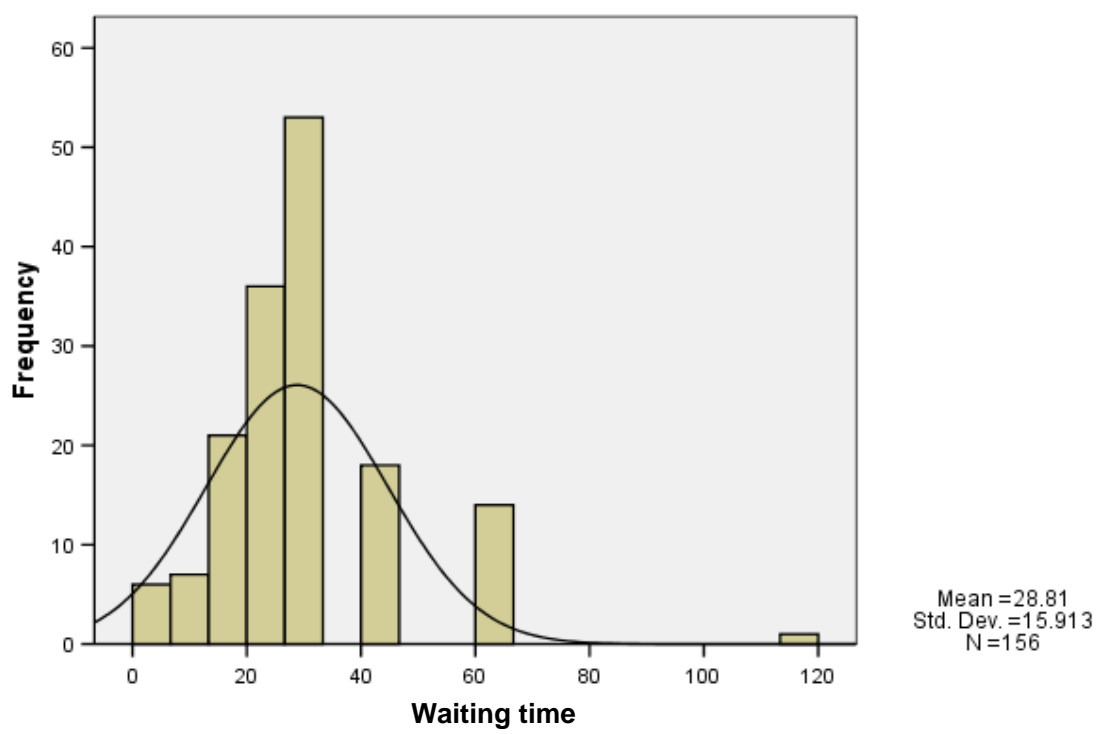

Figure 5. Acceptable queuing at entrance of tourist sites (in minutes) 


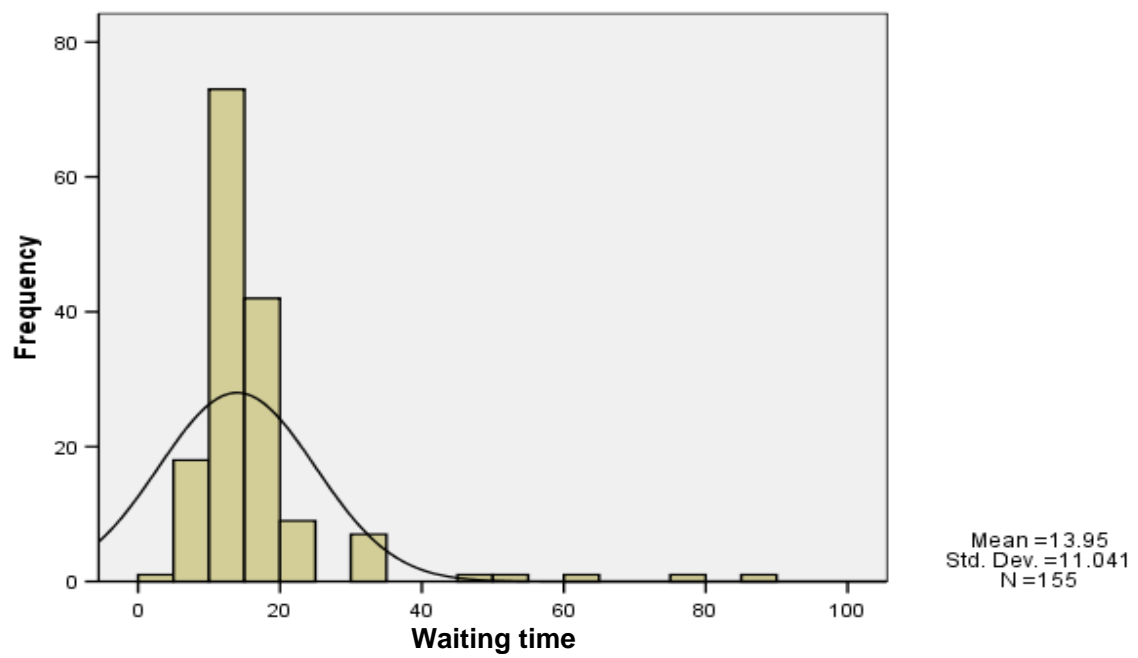

Figure 6. Acceptable waiting time in café’s, bars and restaurants (in minutes)

Next, we will present the statistical results of a regression analysis (OLS estimation) of the WTW for both cultural facilities and café's, bars and restaurants (see Tables 7 and 8). Several sensitivity analyses on various explanatory factors have been carried out, but after a series of statistical experiments it turned out that these findings offer statistically significant and rather robust results.

Table 7 shows that for cultural facilities the WTW is negatively correlated with the dependence of the respondent's income on the cultural sector. When asked about their level of income, respondents were also asked whether their income depended on the cultural tourism sector. This variable showed a good level of significance in our model. Apparently, the level of impatience is a negative function of income, a finding that is also often found in time budget studies. People who work in the sector have a stronger perception of the disutility brought by such delays.

The WTW statistics for the maximum waiting time in café's, bars and restaurants can be found in Table 8. The estimated trip costs (cost that a respondent thinks he/she will have incurred by the end of the trip) and the meals costs per day show a positive correlation with WTW, which sounds plausible as tourists traveling longer distance with high costs tend to accept waiting time in a more relaxed way as part of their overall package, including longer travel. The cost of meals for the entire trip is instead negatively correlated with the willingness to wait to be served in a café/restaurant. This seems to indicate that after a certain threshold, people who are willing to spend more on such items (dining out) would expect a better service. 
Table 7. OLS results for WTW at the entrance of tourist sites (whole sample, N=156)

\begin{tabular}{|c|c|c|c|c|c|c|}
\hline & \multicolumn{2}{|c|}{$\begin{array}{l}\text { Unstandardized } \\
\text { Coefficients }\end{array}$} & \multirow{2}{*}{$\begin{array}{l}\begin{array}{l}\text { Standardized } \\
\text { Coefficients }\end{array} \\
\text { Beta } \\
\end{array}$} & \multirow[b]{2}{*}{$\mathrm{T}$} & \multicolumn{2}{|c|}{$\begin{array}{l}\text { 95\% Confidence } \\
\text { Interval for B }\end{array}$} \\
\hline & $\mathrm{B}$ & Std. Error & & & $\begin{array}{l}\text { Lower } \\
\text { Bound }\end{array}$ & $\begin{array}{l}\text { Upper } \\
\text { Bound }\end{array}$ \\
\hline (Constant) & 46.005 & 6.755 & & 6.811 & 32.660 & 59.350 \\
\hline $\begin{array}{l}\text { Income dependent on cultural } \\
\text { tourism }\end{array}$ & -5.553 & 1.768 & -.244 & -3.141 & -9.046 & -2.060 \\
\hline Economically active & 4.552 & 2.521 & 140 & 1.805 & -.430 & 9.533 \\
\hline
\end{tabular}

Dependent Variable: Queuing at the entrance

Table 8. OLS results for WTW in café's/bars/restaurants (whole sample, N=156)

\begin{tabular}{|c|c|c|c|c|c|c|}
\hline & \multicolumn{2}{|c|}{$\begin{array}{l}\text { Unstandardized } \\
\text { Coefficients }\end{array}$} & \multirow{2}{*}{\begin{tabular}{|l}
$\begin{array}{l}\text { Standardized } \\
\text { Coefficients }\end{array}$ \\
Beta
\end{tabular}} & \multirow[b]{2}{*}{$\mathrm{T}$} & \multicolumn{2}{|c|}{$\begin{array}{l}\text { 95\% Confidence } \\
\text { Interval for B }\end{array}$} \\
\hline & B & Std. Error & & & $\begin{array}{l}\text { Lower } \\
\text { Bound }\end{array}$ & $\begin{array}{l}\text { Upper } \\
\text { Bound }\end{array}$ \\
\hline (Constant) & 9.360 & 1.126 & & 8.311 & 7.134 & 11.585 \\
\hline Estimated trip cost & .002 & .001 & .304 & 3.123 & .001 & .003 \\
\hline Cost meals per day & .122 & .032 & .362 & 3.797 & .059 & .186 \\
\hline Cost meals per trip & -.012 & .005 & -.206 & -2.350 & -.023 & -.002 \\
\hline
\end{tabular}

Dependent Variable: Waiting time in café's/bars/restaurants

Next, we present in Tables 9 and 10 the results of OLS for a subsample of the dataset: the day trippers. One of the questions presented to our respondents allows us to identify the people who are just visiting Amsterdam for a day. They might be coming from a nearby region, or just passing by for other reasons. Though Amsterdam tends to be a prime destination, still the phenomenon of day trippers is present. Non-resident tourists, those who do not spend a night at the destination, have usually other expectations and behaviour. Therefore, it is interesting to see which regression model can better capture this difference.

Table 9. OLS results for WTW at the entrance of tourist sites (day trippers sample, $\mathrm{N}=84$ )

\begin{tabular}{|c|c|c|c|c|c|c|}
\hline & \multicolumn{2}{|c|}{$\begin{array}{l}\text { Unstandardized } \\
\text { Coefficients }\end{array}$} & \multirow{2}{*}{$\begin{array}{l}\begin{array}{l}\text { Standardized } \\
\text { Coefficients }\end{array} \\
\text { Beta }\end{array}$} & \multirow[b]{2}{*}{$\mathrm{T}$} & \multicolumn{2}{|c|}{$\begin{array}{l}\text { 95\% Confidence } \\
\text { Interval for B }\end{array}$} \\
\hline & B & Std. Error & & & $\begin{array}{l}\text { Lower } \\
\text { Bound }\end{array}$ & $\begin{array}{l}\text { Upper } \\
\text { Bound }\end{array}$ \\
\hline (Constant) & 47.444 & 5.775 & & 8.215 & 35.948 & 58.940 \\
\hline Recommend Amsterdam & -16.503 & 5.100 & -.336 & -3.236 & -26.655 & -6.351 \\
\hline Trip cost & .005 & .002 & .867 & 2.259 & .001 & .010 \\
\hline Estimated trip cost & -.015 & .007 & -.830 & -2.186 & -.029 & -.001 \\
\hline Cost tours per day & -.283 & .145 & -.230 & -1.958 & -.571 & .005 \\
\hline
\end{tabular}

Dependent Variable: Queuing at the entrance 
Table 9 shows that the willingness to wait at the entrance of tourists sites is positively correlated to the actual cost of the trip. This is quite rational, since people who incur higher costs to get to the destination are more likely to wait for a longer time to enter the attraction of their choice. WTW to enter such attractions is however, negatively correlated with the cost that the respondent estimates he/she will pay at the end of the trip, with the amount he/she is spending for cultural tours per day and with the question whether he/she would like to recommend Amsterdam as a destination to other tourists. This is in tune with the results from Table 8: people who are willing to spend more on the specific item (cultural attractions) have a specific expectation in terms of the standards that the service should achieve, especially if they intend to recommend the destination.

Table 10. OLS results for WTW in café's/bars/restaurants (day trippers sample, $\mathrm{N}=84$ )

\begin{tabular}{|c|c|c|c|c|c|c|}
\hline \multirow[b]{2}{*}{ Model 1} & \multicolumn{2}{|c|}{$\begin{array}{l}\text { Unstandardized } \\
\text { Coefficients }\end{array}$} & \multirow{2}{*}{$\begin{array}{l}\text { Standardized } \\
\text { Coefficients }\end{array}$} & \multirow[b]{2}{*}{$\mathrm{T}$} & \multicolumn{2}{|c|}{$\begin{array}{l}\text { 95\% Confidence } \\
\text { Interval for B }\end{array}$} \\
\hline & B & Std. Error & & & $\begin{array}{l}\text { Lower } \\
\text { Bound }\end{array}$ & $\begin{array}{l}\text { Upper } \\
\text { Bound }\end{array}$ \\
\hline (Constant) & 7.586 & 1.753 & & 3.196 & 4.099 & 11.074 \\
\hline Cost meals per day & .174 & .055 & .333 & 3.196 & .066 & .283 \\
\hline $\begin{array}{l}\text { Cost transport within } \\
\text { destination per day }\end{array}$ & .567 & .239 & .247 & 2.377 & .092 & 1.042 \\
\hline
\end{tabular}

Dependent Variable: Waiting time in café's/bars/restaurants

Similarly, Table 10 presents the results of OLS for the subsample of day trippers when the dependent variable is the willingness to wait to be served at cafes/bars/restaurants. The WTW in this case is positively correlated with both the cost of meals per day and the costs of transport within the destination per day. The model given by the combination of these two variables can be explained by the fact that if the respondent is willing to pay more for meals and transport at the same time, he/she might be more relaxed in such a situation, since he/she is in a leisure situation and not in a hurry to move to another part of the city.

\section{Concluding Remarks}

The city of Amsterdam is attracting annually large volumes of visitors, where the cultural facilities of the city act as a main attractiveness. Given the relatively small size of 
the city centre where most cultural sites are found, congestion phenomena will likely emerge. Our analysis has tried to assess the WTW of tourists, by using a series of virtual, but realistic scenario experiments on overcrowding in the city. In particular, two types of tourism externalities were statistically analyzed, viz. queuing at entrances of cultural sites and at café's, bars and restaurants. These results offer very interesting findings on differences in WTW and in background factors of these visitors.

As a next step in our analysis, future research might address the behavioural and perceptional motives of tourists by using conjoint analysis as a new statistical tool to identify the driving forces of (im)patience of tourist visitors to Amsterdam. This information may create a wealth of useful input for marketing and policy purposes.

\section{References}

Alberini, A., P. Riganti and L. Longo, Can People Value the Aesthetic and Use Services of Urban Sites? Journal of Cultural Economics, vol. 27, 2003, pp. 193-213.

Buckley, R. (ed.), Environmental Impacts of Ecotourism, CABI Publishing, Wallingford, 2004.

Carruthers, J.I. and B. Mundy (eds.), Environmental Valuation, Ashgate, Aldershot, UK, 2006.

Coccossis, H. and A. Mexa (eds.), The Challenge of Tourism Carrying Capacity Assessment, Ashgate, Aldershot, UK, 2004.

Crouch, G.I. and J.R.B. Ritchie, Tourism, Competitiveness and Societal Prosperity, Journal of Business Research, vol. 44, 1999, pp. 137-152.

Epstein, R.A., The Regrettable Necessity of Contingent Valuation, Journal of Cultural Economics, vol. 27, 2003, pp. 259-275.

Florida, R., Toward the Learning Region, Futures, vol. 27, no. 5, 1995, pp. 527-536.

Giaoutzi, M. and P. Nijkamp (eds.), Tourism and Regional Development; New Pathways, Ashgate, Aldershot, UK, 2006.

Hanley, N., R.E. Wright and V. Adamowicz, Using Choice Experiments to Value the Environment, Environmental and Resource Economics, vol. 11, 1998, pp. 413-428.

Honey, M., Ecotourism and Sustainable Development, Island Press, Washington DC, 1999.

Jakus, P. and W.D. Shaw, Congestion at Recreation Sites, Journal of Environmental Management, vol. 50, 1997, pp. 389-401.

Lindsey, C.R. and E.T. Verhoef, Congestion Modelling, Handbook of Transport Modelling (D.A Hensher and K.J. Button, eds.), Elsevier/Pergamon, Amsterdam, 2000, pp. 353-373.

McCabe, A.S. Tourism Motivation Process, Annals of Tourism Research, vol. 27, no. 4, 2000, pp. 10491052.

McConnell, K.E., Heterogeneous Preferences for Congestion, Journal of Environmental Economics and Management, vol. 5, 1988, pp. 251-258.

Mommaas, H., Cultural Clusters and the Post Industrial City, Urban Studies, vol 41, 2004, pp. 507-532.

Montgomery, J., Cultural Quarters as Mechanisms for Urban Regeneration, Planning Practice and Research, vol 18, 2004, pp. 293-306.

Navrud, S. and R. Ready, Valuing Cultural Heritage, Edward Elgard, Cheltenham, UK, 2002.

Noonan, D.S., Contingent Valuation and Cultural Resources, Journal of Cultural Economics, vol. 27, nos 3/4, 2003, pp. 159-176.

O’Reilly, A.M., Tourism Carrying Capacity - Concepts and Issues, Tourism Management, vol. 7, no. 4, 1986, pp. 254-258.

Poel, P., E. Masurel and P. Nijkamp, The Importance of Friends and Relations in Tourist Behaviour, Tourism and Regional Development (M. Giaoutzi and P. Nijkamp, eds.), Ashgate, Aldershot, UK, 2006, pp. 219-238. 
Saveriades, A., Establishing the Social Tourism Carrying Capacity for the Tourist Resorts of the East Coast of the Republic of Cyprus, Tourism Management, vol. 21, 20000, p. 147-156.

Tallon, A.R., R.D.F. Bromley, B. Reynolds and C.J. Thomas, Developing Leisure and Cultural Attractions in the Regional City Centre: A Policy Perspective, Environment and Planning C, vol. 24, no. 3, 2006, pp. 351-370.

Theobald, W.F. (ed.), Global Tourism, Elsevier, Burlington, Mass, 2005.

Throsby, D., Determining the Value of Cultural Goods, Journal of Cultural Economics, vol. 27, 2003, pp. 275-285.

Towse, R. and A. Khakee (eds.), Cultural Economics, Springer-Verlag, Berlin, 1991.

Wall, G. and A. Mathieson, Tourism, Pearson, Harlow, 2006.

WTO (World Tourist Organization), Tourism Congestion Management and Natural and Cultural Sites, Madrid, 2004. 